\title{
Pharmacists providing care in statewide physician organizations: findings from the Michigan Pharmacists Transforming Care and Quality Collaborative
}

\author{
Antoinette B Coe, PharmD, PhD; Hae Mi Choe, PharmD; Heidi L Diez, PharmD, BCACP; Nicole G Rockey, PharmD, BCACP; \\ Emily J Ashjian, PharmD, BCPS, BCACP; Michael P Dorsch, PharmD, MS, FCCP, FAHA, BCCP; Hyungjin Myra Kim, ScD; \\ and Karen B Farris, PhD, FAPhA
}

\section{What is already known about this subject}

- Primary care providers are tasked with managing an increasing number of chronic health conditions per patient including diabetes, hypertension, and hyperlipidemia, with optimal medication management playing an important role in achievement of patient clinical outcomes as well as clinic-based quality metrics.

- Pharmacists, through disease state management services (DSM) and comprehensive medication reviews (CMR), can improve medicationrelated and clinical outcomes in the primary care setting.
What this study adds

- This study adds an evaluation of a statewide physician organization quality collaborative that incorporated pharmacists to provide DSM and CMR services in primary care.

- This study demonstrates the value of partnership with a payer to support the integration of pharmacists in direct patient care to improve patient outcomes.

- This study demonstrates the value of clinical pharmacists in primary care, since physician organizations retained the pharmacists' services in 16 of 17 organizations.

\section{Author affiliations}

Antoinette B Coe, PharmD, PhD; Michael P Dorsch, PharmD, MS, FCCP, FAHA, BCCP; and Karen B Farris, PhD, FAPhA, University of Michigan College of Pharmacy, Ann Arbor. Hae Mi Choe, PharmD; Heidi L Diez, PharmD, BCACP; and Emily J Ashjian, PharmD, BCPS, $B C A C P$, University of Michigan College of Pharmacy and Michigan Medicine, Ann Arbor. Nicole G Rockey, PharmD, BCACP, Michigan Medicine, Ann Arbor, and Hyungjin Myra Kim, ScD, University of Michigan School of Public Health, Ann Arbor.

\section{AUTHOR CORRESPONDENCE:}

Antoinette B Coe, 734.763.7619,

tonicoe@med.umich.edu

J Manag Care Spec Pharm 2020;26(12):1558-66

Copyright $\odot 2020$, Academy of Managed Care Pharmacy. All rights reserved.

and average visits per patient. Analyses at the encounter level were stratified by 2 encounter types: disease state management (DSM) or comprehensive medication review (CMR). Separately by encounter type, pharmacist effect was described by the number, type, and reasons for medication changes, as well as medication adherence and cost barriers found and addressed Clinical outcomes included hemoglobin Alc 
and blood pressure change. Sustainability and patient satisfaction of pharmacists providing clinical services are reported.

RESULTS: Across 17 POs, 27 pharmacists participated in the MPTCQ program. Pharmacists completed 24,523 patient encounters for DSM with 5,942 patients, with an average of 5 visits per patient with diabetes and 2 visits for hypertension. Pharmacists made 15,153 therapeutic medication changes during visits for diabetes and hypertension, with approximately $70 \%$ related to efficacy. Pharmacists completed 4,203 CMR visits for 3,092 patients. During CMR visits, 1,296 therapeutic medication changes were recommended. Problems with medication cost were identified in $13 \%$ of CMR visits. Blood pressure and Alc levels decreased in patients managed by pharmacists. In 157 patients surveyed, $87 \%$ rated their pharmacists' care as excellent. Sixteen POs retained their pharmacists at the end of funding.

CONCLUSIONS: A statewide provider-payer partnership successfully integrated and retained primary care pharmacists within POs. Pharmacists in the MPTCQ program contributed to improvements in disease control by changing medications to improve patient clinical outcomes.

The number of chronic health conditions among adults in the United States continues to rise, with approximately 27 million adults diagnosed with diabetes and more than 100 million with hypertension. ${ }^{1-3}$ In 2017, approximately $24 \%$ of patients with hypertension had their condition controlled, and nearly 1,300 deaths per day were attributed to hypertension., ${ }^{2,3}$ Likewise, in 2017, diabetes remained the seventh leading cause of death, and estimated total indirect and direct U.S. costs of diagnosed diabetes were approximately $\$ 327$ billion per year. ${ }^{1}$

Optimal medication management plays an important role in achieving patient goals for chronic health conditions. With the potential shortage of primary care providers, one solution is to integrate pharmacists within primary care to support disease and medication management. ${ }^{4-6}$ Pharmacists supporting the primary care team by providing direct patient care improve diabetes, hypertension, and hyperlipidemia outcomes. ${ }^{7-13}$ Pharmacists can also help address the growing polypharmacy problem and provide medication reviews, which examine safety, efficacy, and cost concerns. ${ }^{14-16}$ Although evidence supporting the role and effect of pharmacists on health are prevalent, there are limited studies describing the sustainability of pharmacist services within primary care on a statewide level..$^{17,18}$

Michigan Pharmacists Transforming Care and Quality (MPTCQ) was a program designed to integrate pharmacists within physician organizations' (PO) primary care practices to improve disease state management and medication-related outcomes..$^{19}$ POs are independent primary care practices and/or large group practices that combine clinical leadership with technological and administrative infrastructure to support physician practices. ${ }^{20}$ MPTCQ was a statewide provider-payer partnership in the Blue Cross Blue Shield of Michigan (BCBSM) Collaborative Process Initiative. ${ }^{19}$ This program sought to replicate the successful model of ambulatory care pharmacists within Michigan Medicine patient-centered medical homes across the state. ${ }^{10}$

The MPTCQ Coordinating Center team consisted of pharmacist educators/trainers and project managers that helped PO leadership identify pharmacist transformation champions to integrate a pharmacist model within their physician practices. ${ }^{19}$ The MPTCQ Coordinating Center team provided pharmacist and leadership training and guidance for quality and process improvement across POs and training and support for central data collection and evaluation. BCBSM provided financial support for the pharmacists for the first 2 years of the PO's participation in MPTCQ. ${ }^{19}$ Pharmacists provided disease state management (DSM) under a collaborative practice agreement and comprehensive medication reviews (CMRs) as part of their services.

The purpose of this study was to evaluate the MPTCQ program by (a) describing process outcomes of pharmacist visits within the MPTCQ program; (b) conducting analyses at the encounter level, including DSM or CMR; (c) describing pharmacist effect evaluated by number, type, and reasons for medication changes, medication adherence, and cost barriers found and addressed; (d) analyzing clinical outcomes, including change in blood pressure and hemoglobin A1c (A1c); (e) quantifying patient satisfaction with pharmacist services; and (f) assessing sustainability of pharmacists within the participating POs.

\section{Methods}

MPTCQ had 2 participating cohorts of pharmacists. Data were collected from primary care pharmacist encounters within 17 POs participating in MPTCQ across 2 cohorts over time. In total, 27 pharmacists (17 in cohort 1 and 10 in cohort 2) participated in the MPTCQ program. Cohort 1 started collecting data in July 2016 with 10 POs, and cohort 2 started in October 2016 with 7 POs. Patients were referred to pharmacists by their physicians or identified by pharmacists via registry review for DSM services and/or CMRs. The MPTCQ Coordinating Center collected data using a web-based survey (Qualtrics) to track pharmacist interventions during patient encounters. Data were collected by pharmacists as part of their workflow, using an intervention checklist. 


\section{PROCESS OUTCOMES: DSM AND CMR VISITS}

For every encounter, visits were classified as either DSM or CMR, or both. For DSM visits, data were collected for the disease states (e.g., diabetes or hypertension), and more than 1 disease state could be managed during a visit. Information collected were patient demographics; appointment type (e.g., phone or face-to-face); and pharmacist activities (e.g., lab or test ordered, medication costs addressed and interventions provided, medication adherence addressed, and interventions provided). Medication changes made (e.g., initiate, adjust the dose of, or discontinue a medication) and reason for each medication change (e.g., efficacy, safety, and cost) were also collected. More than 1 reason or type of medication change could be reported. Additional information collected at CMR visits included referrals provided (e.g., for medical evaluation by a physician, visit with dietitian or social worker, and ongoing DSM by the pharmacist); patient goal for CMR participation; and disease states addressed, with more than 1 allowed for the previous items.

\section{CLINICAL OUTCOMES}

Clinical outcomes collected through DSM visits included hemoglobin A1c (A1c) and systolic and diastolic blood pressure (SBP and DBP, respectively). Changes in A1c were evaluated in 2 groups defined by the initial A1c values of $8 \%-8.9 \%$ and $\geq 9 \%$. Analysis included data from patients with at least 2 reported A1c levels separated by at least 3 months. For blood pressure, analysis included patients whose blood pressure measurements were recorded at 2 time points. Patients were categorized into 2 groups based on their initial SBP (140-159 $\mathrm{mmHg}$ and $\geq 160 \mathrm{mmHg}$ ). Patients were then further categorized into 2 DBP groups of $<90$ and $\geq 90$ $\mathrm{mmHg}$ based on initial DBP. Average change in SBP and DBP at most recent follow-up from the initial blood pressure measurement was calculated in each group and cohort.

\section{PATIENT SATISFACTION}

Patients' satisfaction with their MPTCQ pharmacists was measured with a 5-item survey. Four items were assessed using a 5-point scale, and 1 open-ended question for comments was included. Pharmacists provided paper surveys to the patient at the end of a visit. The patient left the completed survey with the front desk clinic staff, and completed surveys were mailed to the MPTCQ Coordinating Center. Pharmacists selected a 1-week block to distribute the survey, with the goal of selecting a week when they had a full schedule, from October 23 to November 30, 2017, for cohort 1 and from May 21 to July 1, 2018, for cohort 2. No identifiable patient information was collected.

\section{SUSTAINABILITY}

Sustainability for this program was defined as the number of pharmacists that participated in the MPTCQ program and remained at the end of 2 years, as well as new pharmacist positions created at the end of funding.

\section{Results}

\section{DSM VISITS}

Table 1 shows outcomes for DSM visits. Pharmacists saw 3,457 unique patients for 13,225 visits in cohort 1 (mean [SD] age 61 [15] years, $56 \%$ women) and 2,485 unique patients for 11,298 visits in cohort 2 (mean [SD] age 62 [14] years, 47\% women).

For cohort 1, pharmacists provided DSM visits for patients with diabetes $(n=10,225)$, hypertension $(n=2,224)$, hyperlipidemia $(n=876)$, asthma $(n=88)$, and other $(n=1,744$; more than 1 disease state could be managed in a visit). Patients with diabetes had an average of 4.8 visits, whereas hypertension, hyperlipidemia, and asthma had a lower number of average visits (1.9, 1.4, and 1.3, respectively). Most visits were by phone (66\%).

In cohort 2 , pharmacists provided DSM visits for patients with diabetes $(n=10,215)$, hypertension $(n=1,715)$, hyperlipidemia $(n=1,239)$, asthma $(n=34)$, and other $(n=737)$. Patients with diabetes had an average of 5.3 visits, and average number of visits for hypertension, hyperlipidemia, and asthma were $2.3,1.9$, and 1.3 , respectively. The majority of visits (57\%) were by phone.

In both cohorts, A1c was the most common laboratory test ordered by MPTCQ pharmacists. Pharmacists identified medication cost problems in $7 \%$ of cohort 1 and $11 \%$ of cohort 2 visits. To address cost concerns, pharmacists most commonly provided medication counseling regarding costs, including referrals to social work, patient assistance programs, or low-cost prescription programs. In $13 \%$ of cohort 1 and $22 \%$ of cohort 2 visits, pharmacists identified medication adherence problems, provided adherence counseling, used motivational interviewing techniques, and recommended an adherence aid.

Pharmacists in cohort 1 and cohort 2 made 15,153 therapeutic medication changes for patients with diabetes, hypertension, hyperlipidemia, and/or asthma. Diabetes management occurred with 4,087 patients, with 12,873 diabetes-related medication changes. The most common diabetes and hypertension medication changes were increasing a dose and adding a medication. The most common hyperlipidemia and asthma medication changes were adding a medication or deleting a medication. Around $70 \%$ of the diabetes and hypertension medication change reasons were related to efficacy. 


\section{TABLE 1 Process Outcomes of Pharmacist-Provided DSM Visits, Cohorts 1 and 2}

Pharmacist Activities by Visit ${ }^{\mathrm{a}}$ Labs/tests ordered

\begin{tabular}{|c|c|c|c|}
\hline Alc & $1,411 \quad(10.7)$ & 1,083 & (9.6) \\
\hline Basic metabolic panel & $(3.2)$ & 259 & $(2.3)$ \\
\hline Urine microalbumin & $361 \quad(2.7)$ & 361 & $(3.2)$ \\
\hline Cholesterol & $(2.5)$ & 296 & (2.6) \\
\hline Comprehensive metabolic panel & $263 \quad(2.0)$ & 240 & (2.1) \\
\hline Eye exam referral & 110 & 378 & $(3.3)$ \\
\hline Other & $(6.9)$ & 268 & $(2.4)$ \\
\hline None & $10,485 \quad(79.3)$ & 9,553 & $(84.6)$ \\
\hline \multicolumn{4}{|l|}{ Medication costs addressed ${ }^{b}$} \\
\hline Medication cost problem identified after assessment & $(7.2)$ & 1,251 & $(11.1)$ \\
\hline No problems identified after assessment & $10,998 \quad(83.2)$ & 7,613 & $(67.4)$ \\
\hline Not addressed & 1,271 & 2,433 & $(21.5)$ \\
\hline \multicolumn{4}{|l|}{ Medication cost interventions } \\
\hline Provided medication counseling & $410 \quad(3.1)$ & 555 & $(4.9)$ \\
\hline Referred to social work or patient assistance program & $(1.6)$ & 205 & $(1.8)$ \\
\hline Referred patient to free $/ \$ 4$ prescription program & $(1.2)$ & 360 & $(3.2)$ \\
\hline Consulted physician & $(1.0)$ & 102 & $(0.9)$ \\
\hline Changed medication & $(0.7)$ & 219 & $(1.9)$ \\
\hline Contacted insurance/assisted with prior authorization & $\mathrm{N} / \mathrm{A}$ & 152 & $(1.3)$ \\
\hline Other & $378 \quad(2.9)$ & 202 & $(1.8)$ \\
\hline None & $14 \quad(0.1)$ & 25 & $(0.2)$ \\
\hline \multicolumn{4}{|l|}{ Medication adherence addressed $^{\mathrm{c}}$} \\
\hline Medication adherence problem identified after assessment & $1,721 \quad(13.0)$ & 2,503 & $(22.2)$ \\
\hline No problems identified after assessment & $10,771 \quad(81.4)$ & 8,258 & (73.1) \\
\hline Not addressed & $719 \quad(5.4)$ & 536 & $(4.7)$ \\
\hline \multicolumn{4}{|l|}{ Medication adherence interventions } \\
\hline Provided medication counseling & $1,454(11.0)$ & 1,929 & $(17.1)$ \\
\hline Used motivational interviewing to improve adherence & $(5.7)$ & 965 & $(8.5)$ \\
\hline Recommended adherence aid (e.g., pillbox, alarm, medication list) & $(2.0)$ & 734 & $(6.5)$ \\
\hline Consulted physician & $(1.8)$ & 178 & $(1.6)$ \\
\hline Recommended medication change & $\mathrm{N} / \mathrm{A}$ & 198 & $(1.8)$ \\
\hline Other & $214 \quad(1.6)$ & 91 & $(0.8)$ \\
\hline None & $(0.1)$ & 22 & $(0.2)$ \\
\hline
\end{tabular}

continued on next page

\section{Cohort 1 ( $n=13,225$ visits) \\ Cohort 2 ( $n=11,298$ visits)}

n (\%)

n (\%)

\section{Alc}

Urine microalbumin

Cholesterol

Comprehensive metabolic pane

Eye exam referra

Other

None

Medication costs addressed

Medication cost problem identified after assessment

No problems identified after assessment

Not addressed

Medication cost interventions

Provided medication counseling

Referred to social work or patient assistance program

Referred patient to free/ $\$ 4$ prescription program

Consulted physician

anged medication

Contacted insurance/assisted with prior authorization

Othe

Medication adherence addressed ${ }^{c}$

Medication adherence problem identified after assessment

No problems identified after assessment 


\section{TABLE 1 Process Outcomes of Pharmacist-Provided DSM Visits, Cohorts 1 and 2 (continued)}

Overall Summary of Pharmacist-Provided Therapeutic Medication Changes by Disease State

\begin{tabular}{|c|c|c|c|c|c|c|c|c|}
\hline \multirow{2}{*}{$\begin{array}{l}\text { Disease state } \\
\text { Cohort } \\
\end{array}$} & \multicolumn{2}{|c|}{ Diabetes } & \multicolumn{2}{|c|}{ Hypertension } & \multicolumn{2}{|c|}{ Hyperlipidemia } & \multicolumn{2}{|c|}{ Asthma } \\
\hline & 1 & 2 & 1 & 2 & 1 & 2 & 1 & 2 \\
\hline Patients seen for the condition, $\mathrm{n}$ & 2,149 & 1,938 & 1,167 & 755 & 606 & 664 & 70 & 26 \\
\hline Patients with a medication change, $n$ & 1,527 & 1,416 & 520 & 259 & 271 & 245 & 26 & 5 \\
\hline Medication changes for the condition, $\mathrm{n}$ & 6,367 & 6,506 & 917 & 499 & 390 & 426 & 40 & 8 \\
\hline \multicolumn{9}{|l|}{ Type of therapeutic medication change, $n$} \\
\hline Added medication & 1,273 & 1,322 & 323 & 148 & 221 & 203 & 22 & 5 \\
\hline Deleted medication & 729 & 783 & 183 & 91 & 104 & 106 & 8 & 3 \\
\hline Increased dose & 3,253 & 3,144 & 291 & 173 & 44 & 91 & 5 & 0 \\
\hline Decreased dose & 717 & 885 & 60 & 53 & 10 & 15 & 0 & 0 \\
\hline Optimized medication to improve therapy & 395 & 372 & 60 & 34 & 11 & 11 & 5 & 0 \\
\hline \multicolumn{9}{|l|}{ Reason for medication change, $n$} \\
\hline Efficacy & 4,628 & 4,383 & 710 & 349 & 260 & 294 & 27 & 2 \\
\hline Safety & 1,392 & 1,555 & 164 & 138 & 103 & 113 & 5 & 0 \\
\hline Cost & 516 & 391 & 53 & 20 & 57 & 37 & 8 & 4 \\
\hline
\end{tabular}

aPatients could have more than 1 visit type or intervention provided. Percentages are calculated out of $n=13,225$ visits for cohort 1 and $n=11,298$ visits for cohort 2 unless indicated otherwise.

${ }^{b}$ Cohort $1, n=13,219$ visits.

'Cohort 1, $n=13,221$ visits.

$D S M=$ disease state management; $N / A=$ not applicable.

\section{CMR VISITS}

Outcomes for CMR visits are shown in Table 2. MPTCQ pharmacists saw 2,339 unique patients (mean [SD] age 63 [16] years, 61\% women) for 2,972 CMR visits in cohort 1 and 753 patients (61 [14] years, 59\% women) for 1,231 CMR visits in cohort 2.

The mean (SD) number of medications per patient was 8.2 (4.9) for cohort 1 and 10.4 (5.3) for cohort 2. The most common patient-identified reasons or goals for their participation were doctor recommendation $(\mathrm{n}=876$, cohort 1 ; $\mathrm{n}=323$, cohort 2); manage health condition $(\mathrm{n}=825$, cohort 1 ; $\mathrm{n}=103$, cohort 2); and medication side effects or safety $(\mathrm{n}=609$, cohort $1 ; \mathrm{n}=288$, cohort 2). Most CMR visits were face-to-face in cohort $1(n=1,960,66 \%)$ compared with by phone in cohort $2(\mathrm{n}=768,62 \%)$. The average (SD) number of CMR visits per patient was 1.3 (0.8) for cohort 1 and 1.6 (2.1) for cohort 2.

Pharmacists identified medication adherence problems in $27 \%$ and $21 \%$ of CMR visits in cohort 1 and cohort 2, respectively. Medication cost problems were identified in approximately $13 \%$ of visits in both cohorts. Referrals were common outcomes of the CMRs in cohort 1, with approximately $25 \%$ of visits referred for additional pharmacist DSM,
$17 \%$ for medical evaluation, and $10 \%$ referred to other health care team members. Lower proportions of referrals were observed in cohort 2. In CMRs provided to patients with diabetes, hypertension, hyperlipidemia, and/or asthma, 1,296 therapeutic medication changes were recommended, with 791 related to efficacy and 433 related to safety.

\section{CLINICAL OUTCOMES}

A1c. In cohort 1, 221 patients had their initial A1c of 8.0\%-8.9\%, and mean change in A1c after at least 3 months was $-0.8 \%$ (range $-3.2-5.2 \%)$. For cohort 2, $(n=268)$, the mean change in A1c was $-0.9 \%$ (range $-3.5-3.6 \%$ ). In cohort 1,333 patients had their initial A1c of $\geq 9 \%$, and their average change in A1c was $-1.9 \%$ (range $-9.2-5.0 \%)$. In cohort $2(n=531)$, the mean change in A1c was $-2.5 \%$ (range to $-10.6-3.2 \%$ ).

Blood Pressure. Group 1 (initial SBP 140-159 mmHg, DBP $<90 \mathrm{mmHg}$ ) included 109 cohort 1 patients with an average SBP change of -4.3 (range -37-38) and 149 cohort 2 patients with an average SBP change of -5.6 (range $-50-38$ ).

Group 2 (initial SBP 140-159 $\mathrm{mmHg}$, DBP $\geq 90 \mathrm{mmHg}$ ) included 66 cohort 1 patients with an average SBP change of -11 (range $-40-30$ ) and DBP change -11.2 (range $-42-10$ ), 


\section{TABLE 2 Process Outcomes of Pharmacist-Provided CMR Visits, Cohorts 1 and 2}

\section{Pharmacist Activities by Visit ${ }^{\mathrm{a}}$}

\section{Referrals placed}

PharmD for disease state management

Medical evaluation (e.g., MD, NP, PA)

Other health care team member (e.g., social work, nutrition)

\section{Disease state addressed}

\begin{tabular}{l} 
Hypertension \\
\hline Hyperlipidemia \\
\hline Depression/anxiety \\
\hline Diabetes \\
\hline Anticoagulation \\
\hline COPD \\
\hline Asthma \\
\hline Heart failure \\
\hline Osteoporosis \\
\hline Other
\end{tabular}

\section{Labs/tests ordered}

\begin{tabular}{|c|c|c|c|}
\hline Alc & $153 \quad(5.1)$ & 14 & $(1.1)$ \\
\hline Basic metabolic panel & $(3.4)$ & 3 & $(0.2)$ \\
\hline Cholesterol & $(3.4)$ & 5 & $(0.4)$ \\
\hline Comprehensive panel & $77 \quad(2.6)$ & 8 & $(0.6)$ \\
\hline Urine microablumin & $(1.7)$ & 7 & $(0.6)$ \\
\hline Thyroid stimulating hormone/thyroxine (TSH/T4) & $(1.1)$ & 4 & $(0.3)$ \\
\hline Foot exam completed & $1(0.03)$ & 0 & $(0.0)$ \\
\hline Other & $145 \quad(4.9)$ & 49 & $(4.0)$ \\
\hline None & $2,561 \quad(86.2)$ & 1,159 & $(94.2)$ \\
\hline \multicolumn{4}{|l|}{ Medication costs ${ }^{b}$} \\
\hline Medication cost problem identified after assessment & $399(13.4)$ & 169 & $(13.7)$ \\
\hline No problems identified after assessment & $2,440 \quad(82.1)$ & 674 & $(54.8)$ \\
\hline Not addressed & $(4.3)$ & 388 & $(31.5)$ \\
\hline \multicolumn{4}{|l|}{ Medication cost interventions provided ${ }^{a}$} \\
\hline Provided medication counseling & $(5.3)$ & 91 & (7.4) \\
\hline Referred to social work or patient assistance program & $(3.0)$ & 28 & $(2.3)$ \\
\hline Referred patient to free/ $\$ 4$ prescription program & $(2.8)$ & 52 & $(4.2)$ \\
\hline Consulted physician & $(1.9)$ & 33 & $(2.7)$ \\
\hline Changed prescription to a lower cost medication & $\mathrm{N} / \mathrm{A}$ & 17 & $(1.4)$ \\
\hline Contacted insurance/assisted with prior authorization & $\mathrm{N} / \mathrm{A}$ & 7 & $(0.6)$ \\
\hline Other & $160 \quad(5.4)$ & 34 & $(2.8)$ \\
\hline None & $(0.3)$ & 0 & $(0.0)$ \\
\hline
\end{tabular}

continued on next page
Cohort 1 ( $n=2,972$ visits)

n (\%)

n (\%)

\begin{tabular}{|rr|rr}
748 & $(25.2)$ & 74 & $(6.0)$ \\
494 & $(16.6)$ & 80 & $(6.5)$ \\
285 & $(9.6)$ & 22 & $(1.8)$
\end{tabular}

\begin{tabular}{rr|rr}
\hline 1,613 & $(54.3)$ & 297 & $(24.1)$ \\
1,314 & $(44.2)$ & 218 & $(17.7)$ \\
1,010 & $(34.0)$ & 380 & $(30.9)$ \\
973 & $(32.7)$ & 279 & $(22.7)$ \\
293 & $(9.9)$ & 57 & $(4.6)$ \\
284 & $(9.6)$ & 113 & $(9.2)$ \\
254 & $(8.5)$ & 68 & $(5.5)$ \\
139 & $(4.7)$ & 68 & $(5.5)$ \\
137 & $(4.6)$ & 17 & $(1.4)$ \\
1,325 & $(44.6)$ & 731 & $(59.4)$
\end{tabular}

Cohort 2 ( $n=1,231$ visits)

$\mid$

\begin{tabular}{|l|l|}
\hline \\
\hline \\
\hline \\
\hline
\end{tabular}




\section{TABLE 2 Process Outcomes of Pharmacist-Provided CMR Visits, Cohorts 1 and 2 (continued)}

Pharmacist Activities by Visit ${ }^{a}$

\section{Medication adherence ${ }^{c}$}

Medication adherence problem identified after assessment

No problems identified after assessment

Not addressed

Medication adherence interventions provided

Provided medication counseling

Used motivational interviewing to improve adherence

Recommended adherence aid (e.g., pillbox, alarm, medication list)

Consulted physician

Recommended medication change

Other

None

\begin{tabular}{c|c} 
Cohort 1 ( $n=2,972$ visits) & Cohort 2 ( $=1,231$ visits) \\
\hline$n(\%)$ & $n(\%)$ \\
\hline
\end{tabular}

\begin{tabular}{|rr|rr|}
787 & $(26.5)$ & 257 & $(20.9)$ \\
\hline 2,088 & $(70.3)$ & 875 & $(71.1)$ \\
90 & $(3.0)$ & 99 & $(8.0)$ \\
\hline
\end{tabular}

\begin{tabular}{|rr|rr|}
$670(22.5)$ & 213 & $(17.3)$ \\
\hline $315 \quad(10.6)$ & 47 & $(3.8)$ \\
$189 \quad(6.4)$ & 91 & $(7.4)$ \\
\hline $169 \quad(5.7)$ & 42 & $(3.4)$ \\
\hline \multicolumn{2}{|c|}{$\mathrm{N} / \mathrm{A}$} & 15 & $(1.2)$ \\
\hline $124 \quad(4.2)$ & 16 & $(1.3)$ \\
\hline $3 \quad(0.1)$ & 0 & $(0.0)$ \\
\hline
\end{tabular}

Overall Summary of Pharmacist-Provided Therapeutic Medication Changes by Disease State

\begin{tabular}{|c|c|c|c|c|c|c|c|c|}
\hline \multirow{2}{*}{$\begin{array}{l}\text { Disease state } \\
\text { Cohort }\end{array}$} & \multicolumn{2}{|c|}{ Diabetes } & \multicolumn{2}{|c|}{ Hypertension } & \multicolumn{2}{|c|}{ Hyperlipidemia } & \multicolumn{2}{|c|}{ Asthma } \\
\hline & 1 & 2 & 1 & 2 & 1 & 2 & 1 & 2 \\
\hline Patients seen for the condition, $n$ & 769 & 211 & 1,316 & 236 & 1,098 & 187 & 232 & 57 \\
\hline Patients with a medication change, $\mathrm{n}$ & 272 & 63 & 238 & 52 & 201 & 36 & 68 & 16 \\
\hline Total medication changes for the condition, $\mathrm{n}$ & 391 & 96 & 335 & 74 & 251 & 48 & 82 & 19 \\
\hline \multicolumn{9}{|l|}{ Type of therapeutic medication changes, $n$} \\
\hline Added medication & 116 & 24 & 96 & 8 & 109 & 15 & 36 & 3 \\
\hline Deleted medication & 88 & 35 & 92 & 31 & 77 & 21 & 14 & 6 \\
\hline Increased dose & 89 & 25 & 60 & 15 & 23 & 6 & 9 & 3 \\
\hline Decreased dose & 49 & 10 & 44 & 9 & 9 & 2 & 1 & 0 \\
\hline Optimized medication to improve therapy & 49 & 9 & 43 & 13 & 33 & 5 & 22 & 8 \\
\hline \multicolumn{9}{|l|}{ Reason for medication change, $n$} \\
\hline Efficacy & 233 & 52 & 203 & 33 & 171 & 23 & 62 & 14 \\
\hline Safety & 157 & 32 & 130 & 28 & 51 & 18 & 14 & 3 \\
\hline Cost & 57 & 10 & 17 & 4 & 26 & 10 & 11 & 1 \\
\hline Not indicated & 2 & 2 & 3 & 8 & 8 & 7 & 1 & 2 \\
\hline
\end{tabular}

apatients could have more than 1 referral, disease state addressed, lab/test ordered, or intervention provided. Percentages are calculated out of $n=2,972$ visits for cohort 1 and $n=1,231$ visits for cohort 2 unless indicated.

${ }^{b}$ Cohort $1, n=2,967$ visits.

'Cohort $1, n=2,965$ visits.

$C M R=$ comprehensive medication review; $C O P D=$ chronic obstructive pulmonary disease; $M D=$ doctor of medicine; $N / A=$ not applicable; $N P=$ nurse practitioner; $P A=$ physician assistant; $P$ harm $D=$ doctor of pharmacy

and 61 cohort 2 patients with an average SBP change of -12.1 (range -44-18) and DBP change -9.7 (range -40-12).

Group 3 (initial SBP $\geq 160 \mathrm{~mm} \mathrm{Hg}, \mathrm{DBP}<90 \mathrm{mmHg}$ ) included 30 cohort 1 patients with an average SBP change of
-23.2 (range -76-18) and 31 cohort 2 patients with an average SBP change of -24.6 (range $-52-10$ ).

Group 4 (initial SBP $\geq 160 \mathrm{mmHg}$, DBP $\geq 90 \mathrm{mmHg}$ ) included 37 cohort 1 patients with an average SBP change of 
-30.1 (range -66-6) and DBP change of -14.7 (range $-38-10$ ), and 28 cohort 2 patients with an average SBP change of -26.5 (range -100-19) and DBP change of -14.8 (range $-50-12$ ).

\section{PATIENT SATISFACTION}

Of 78 patient surveys distributed in cohort 1, 70 were returned (response rate: 90\%), and all 79 patient surveys distributed in cohort 2 were returned (response rate: 100\%). All surveyed patients in both cohorts either strongly agreed or agreed that the pharmacist explained things in a way that was easy to understand and helped them make the best use of their medications. The majority (98\% in cohort 1 and $100 \%$ in cohort 2) strongly agreed or agreed that they trusted the pharmacist to help manage their medical conditions, and $87 \%$ of the patients in both cohorts rated their pharmacist care as excellent. Example patient comments were "I feel more confident of the goals needed of this medication when the pharmacist explains it" and "After my first visit, I feel encouraged and supported to begin to manage my health condition and look forward to my next visit."

\section{SUSTAINABILITY AND CHALLENGES/ADAPTATIONS OVER TIME}

Twenty-seven pharmacists participated in the MPTCQ program. For cohort 1 , at the end of 2 years, 9 out of the 10 POs continued with a pharmacist or added additional pharmacists. One PO in cohort 1 dropped out at 1 year. At the end of 2 years for cohort 2 , all pharmacists were retained. Of note, $1 \mathrm{PO}$ in cohort 2 added 8 additional pharmacists.

The MPTCQ pharmacists experienced practice-related challenges. Almost all MPTCQ pharmacists were new to their practice sites. Time was required to build their patient panel. Space and patient room challenges were a concern. Some pharmacists were integrated within several practices in $1 \mathrm{PO}$, and each practice had a different electronic medical record system. Additionally, there was pharmacist turnover during the program, which required additional recruitment and MPTCQ pharmacist training.

Additional data collection training supported by the MPTCQ Coordinating Center was needed as new questions or issues emerged and to adapt to practice needs over time. For instance, collection of blood pressure and diabetes clinical outcomes were delayed in cohort 1 to allow processes and pharmacist training to be established. Also, medication cost and adherence intervention options were added or deleted based on feedback from the pharmacists and preliminary analysis of cohort 1 data.

\section{Discussion}

MPTCQ pharmacists were successfully integrated into statewide primary care practices among 17 POs that had not previously had a pharmacist as part of their care teams or aimed to expand existing pharmacist services. Across the 2 cohorts, MPTCQ pharmacists provided DSM or CMR services to over 9,000 patients. A large number of medication safety- and efficacy-related interventions were reported by pharmacists, which supported optimization of performance on medication-related quality measures and also addressed patient concerns about costs and barriers to medication adherence. ${ }^{19}$ MPTCQ pharmacists also contributed to quality of care for their patients by ordering A1c, urine microalbumin, and cholesterol tests and placing eye exam referrals.

Similar to the Health-Systems for Integrated Medication Management, a Minnesota pharmacist collaborative, ${ }^{18}$ MPTCQ recognizes that financial pressures on POs will continue to increase and that the need to show value and effect on quality metrics by pharmacist services in primary care is essential to retain these services. This statewide providerpayer partnership offered a novel strategy to increase inclusion of pharmacists within the primary care team.

\section{LIMITATIONS}

This study has some limitations to consider. One such limitation was the lack of access to claims data to link pharmacist interventions to outcomes such as hospital admissions, medication adherence, or total cost of care. Also, cohort 1 data collection was delayed to allow for creation and implementation of the data collection tools, and not all patients had clinical measures reported. MPTCQ information was limited to Michigan pharmacists, which may limit generalizability to other states because of differing state practice laws and payer systems. Finally, there was potential for social desirability bias in the patient satisfaction survey responses.

\section{Conclusions}

A statewide provider-payer partnership successfully integrated and sustained primary care pharmacists within physician organizations. Pharmacists within the MPTCQ program contributed to disease state and medication management to support the primary care team and improve patient outcomes. 


\section{DISCLOSURES}

Support for MPTCQ was provided by Blue Cross and Blue Shield of Michigan (BCBSM) as part of the BCBSM Value Partnerships program. Coe was supported by the National Center for Advancing Translational Sciences of the National Institutes of Health under award number KL2TR002241. Although BCBSM and MPTCQ work collaboratively, the opinions, beliefs, and viewpoints expressed by the authors do not necessarily reflect the opinions, beliefs, and viewpoints of BCBSM or any of its employees. The content is solely the responsibility of the authors and does not necessarily represent the official views of the National Institutes of Health. The authors have no conflicts of interest to report.

\section{ACKNOWLEDGMENTS}

The authors acknowledge Julie Geyer, BBA, program manager, and Sandra Becker, MA, data analyst, for their contributions.

\section{REFERENCES}

1. Centers for Disease Control and Prevention. National diabetes statistics report 2020. Estimates of diabetes and its burden in the United States. Accessed November 11, 2020. https://www.cdc.gov/ diabetes/pdfs/data/statistics/nationaldiabetes-statistics-report.pdf

2. Centers for Disease Control and Prevention. Facts about hypertension. Accessed November 11, 2020. https:// www.cdc.gov/bloodpressure/facts.htm

3. Virani SS, Alonso A, Benjamin EJ, et al. Heart disease and stroke statistics2020 update: a report from the American Heart Association. Circulation. 2020;141(9):e139-e596.

4. Bodenheimer TS, Smith MD. Primary care: proposed solutions to the physician shortage without training more physicians. Health Aff (Millwood). 2013;32(11):1881-86.
5. Smith M, Bates DW, Bodenheimer T, Cleary PD. Why pharmacists belong in the medical home. Health Aff (Millwood). 2010;29(5):906-13

6. Smith M, Bates DW, Bodenheimer TS. Pharmacists belong in accountable care organizations and integrated care teams. Health Aff (Millwood). 2013;32(11):1963-70.

7. Benedict AW, Spence MM, Sie JL, et al. Evaluation of a pharmacist-managed diabetes program in a primary care setting within an integrated health care system. J Manag Care Spec Pharm. 2018;24(2): 114-22. doi: 10.18553/jmcp.2018.24.2.114

8. Chisholm-Burns MA, Kim Lee J, Spivey CA, et al. US pharmacists' effect as team members on patient care: systematic review and meta-analyses. Med Care. 2010;48(10):923-33.

9. Choe HM, Bernstein SJ, Mueller BA, Walker PC, Stevenson JG, Standiford CJ. Pharmacist leads primary care team to improve diabetes care. Am J Health Syst Pharm. 2009;66(7):622-24.

10. Choe HM, Farris KB, Stevenson JG, et al. Patient-centered medical home: developing, expanding, and sustaining a role for pharmacists. Am J Health Syst Pharm. 2012;69(12):1063-71.

11. Hirsch JD, Steers N, Adler DS, et al. Primary care-based, pharmacist-physician collaborative medication-therapy management of hypertension: a randomized, pragmatic trial. Clin Ther. 2014;36(9):1244-54.

12. Carter BL, Bergus GR, Dawson JD, et al. A cluster randomized trial to evaluate physician/pharmacist collaboration to improve blood pressure control. J Clin Hypertens (Greenwich). 2008;10(4):260-71.

13. Edwards HD, Webb RD, Scheid DC, Britton ML, Armor BL. A pharmacist visit improves diabetes standards in a patientcentered medical home (PCMH). Am J Med Qual. 2012;27(6):529-34.
14. Kantor ED, Rehm CD, Haas JS, Chan AT, Giovannucci EL. Trends in prescription drug use among adults in the United States from 1999-2012. JAMA. 2015;314(17):1818-31.

15. Moczygemba LR, Goode JV, Gatewood SB, et al. Integration of collaborative medication therapy management in a safety net patient-centered medical home. J Am Pharm Assoc. 2011;51(2):167-72.

16. Coe AB, Choe HM. Pharmacists supporting population health in patientcentered medical homes. Am J Health Syst Pharm. 2017;74(18):1461-66.

17. Dolovich L, Pottie K, Kaczorowski J, et al. Integrating family medicine and pharmacy to advance primary care therapeutics. Clin Pharmacol Ther. 2008;83(6):913-17.

18. Kastner MR, Merk ZJ. Sustaining ambulatory comprehensive medication management practices: perspectives from a Minnesota Pharmacist Collaborative. J Manag Care Spec Pharm. 2018;24(12): 1264-68. doi: 10.18553/jmcp.2018.24.12.1264

19. Choe HM, Lin AT, Kobernik K, et al. Michigan pharmacists transforming care and quality: developing a statewide collaborative of physician organizations and pharmacists to improve quality of care and reduce costs. J Manag Care Spec Pharm. 2018;24(4):373-78. doi: 10.18553/ jmcp.2018.24.4.373

20. Lemak CH, Nahra TA, Cohen GR, et al. Michigan's fee-for-value physician incentive program reduces spending and improves quality in primary care. Health Aff (Millwood). 2015;34(4):645-52. 